\title{
A clinical exercise system for paraplegics using functional electrical stimulation
}

\author{
L A Bremner MSc, ${ }^{1} \mathrm{~K}$ E Sloan MSc,${ }^{1} \mathrm{R}$ E Day MBiomedEng, ${ }^{1}$ E R Scull BE FIE \\ (Aust), ${ }^{1} \mathrm{~T}$ Ackland $\mathrm{PhD}^{2}$
}

${ }^{1}$ Department of Medical Physics, Royal Perth Hospital, Perth, Australia; ${ }^{2}$ Department of Human Movement and Recreation, University of Western Australia, Perth, Australia.

\begin{abstract}
A low cost clinical exercise system was developed for the spinal cord injured, based on a bicycle ergometer and electrical stimulation. A pilot project was conducted, using the system, to examine the effects of stimulation induced cycling in long term paraplegics. The project comprised 2 phases of exercise, a strengthening phase involving a 12 week programme of electrical stimulation to the quadriceps and hamstrings and a 12 week cycling phase. Physiological, morphological and biochemical parameters were measured for each subject, at the beginning of the programme and following each phase. Results showed that a programme of stimulation induced lower limb exercise increased the exercise tolerance of all patients, as determined by a progressive increase in exercise time, cycling rate and exercise load. The enhanced exercise tolerance was a result of increases in local muscle strength and endurance. Increases in thigh muscle area and joint range of motion were recorded and all incomplete subjects reported an improvement in functional capabilities and general wellbeing.
\end{abstract}

Key words: functional electrical stimulation; bicycle ergometry; paraplegia; spinal cord injury.

\section{Introduction}

Following a spinal cord injury rapid degenerative changes occur to the body as a result of the associated immobilisation and inactivity. These changes may lead to such long term health problems as cardiovascular disease, thrombosis and pressure sores. ${ }^{1}$ Functional electrical stimulation (FES) has been used extensively to exercise the lower limbs of people with spinal cord injury to prevent such secondary complications.

Stimulation induced cycling, which combines a reconditioning programme with functional movement, has been shown to increase muscle bulk and density, improve muscle strength and endurance and increase cardiovascular fitness. ${ }^{2-9}$

However many of the systems used in previous studies have been laboratory bound or expensive to produce. This paper documents the development of a low cost, clinical exercise system for the spinal injured based on a bicycle ergometer and portable electrical stimulation units. A pilot project was conducted, using the system, to examine the effects of stimulation induced cycling in long term paraplegics.

\section{Exercise system}

A Maximiser 3000 recumbent exercise cycle was purchased and modified for the project (Fig 1). A wider seat with protective foam cushioning and a high moulded backrest were added. The angle of the backrest, height of the seat and distance to the pedals were made adjustable, with the backrest extendable to a horizontal position. Drop down handles were fitted to each side of the seat for lateral support and wooden feet, placed either end of the cycle frame, were added to improve stability.

A baseplate was attached to each pedal to enable the subject's foot to be strapped in. A stabilising bar, fixed to the pedal to support the lower limb in the saggital plane, limited ankle plantar/dorsiflexion and knee varus/valgus movement. Padding was attached to all straps and the bar to prevent 


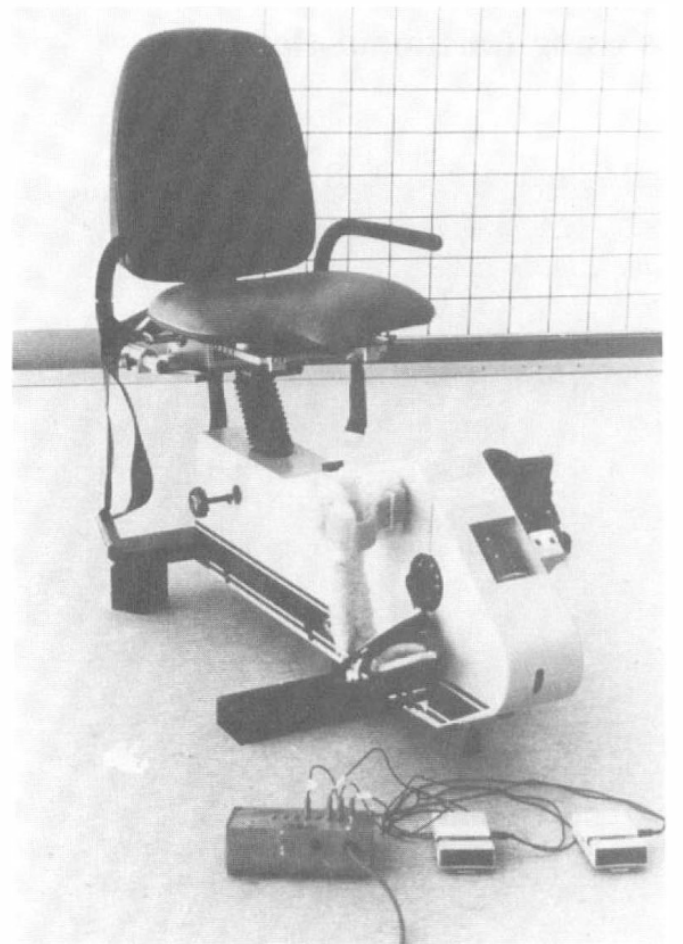

Figure 1 Modified exercise cycle.

pressure areas. The original freewheel clutch was replaced by a fixed sprocket enabling the momentum of the flywheel to be transferred to the pedals, smoothing the energy demand on the user. A rotary shaft encoder was connected to the crank of the cycle via a toothed belt, and geared to emit 360 pulses for one revolution of the pedals. A microswitch and cam, mounted near and on the crank respectively, provided an absolute reference point. The pulse count was reset after each complete revolution of the crank. The pulse information from the encoder was sent to the serial port of an Epson Ax IBM compatible computer via a Microsoft mouse interface. A control program, written in QuickBASIC, accumulated the shaft encoder pulses to determine crank angle. This angle was compared with the on/off sequences required for the stimulation units in use, which were then activated accordingly. Eight channels of stimulation could be controlled simultaneously. Stimulation was applied using commercially avail- able dual channel Myocare portable stimulators (Fig 2). These units were programmed using a small Epson HX20 computer to produce biphasic pulses 298 microseconds in duration at a frequency of $35 \mathrm{~Hz}$. The maximum amplitude was set at $81 \mathrm{~mA}$. Selection of the stimulation parameters was based on the findings of previous investigators. ${ }^{10-12}$ The stimulation units were modified for remote switching, each channel operating independently. The stimulation was applied to the subject via surface electrodes. Switching of the stimulation channels was done using an 8 channel relay box connected to the parallel port of the computer. This read an 8 bit data word and latched the output relays, and therefore the channels, on and off as appropriate. The timing sequence for each stimulation channel was entered into the control program by the operator. Each subject's program could be saved, recalled and modified as needed. The software provided a real time display of cycling speed in rpm, duration of cycling, crank angle and stimulation activation. At the end of each cycling session total cycling time and maximum, minimum and average speeds were displayed.

\section{Subject selection}

To obtain subjects for the pilot project a survey was sent to a sample population of 173 spinal injured people, all at least one year post injury. From 70 survey responses 12 people were selected. Initial selection criteria included a spinal lesion between T6

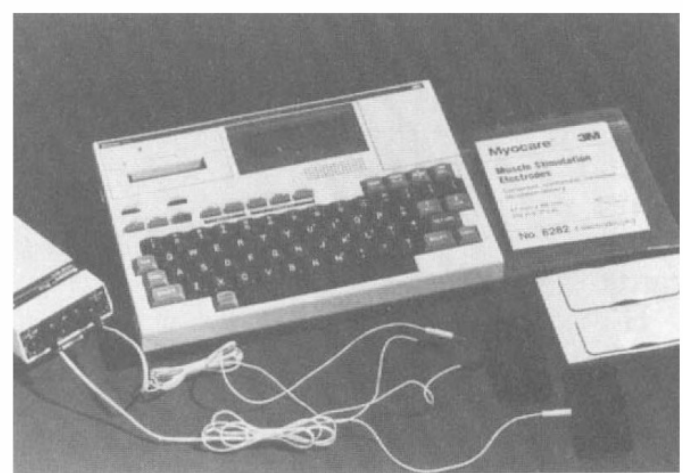

Figure 2 Portable electrical stimulation units used. 
and T12/L1, 40 years of age or less and a willingness and motivation to participate in the program. A further selection process (Table I) reduced the sample size to 6 .

The final group (Table II) consisted of 4 subjects with incomplete spinal injuries and 2 with complete. Two incomplete subjects with mixed motor neuron lesions (upper and lower) were included in the project. Subsequently one male subject with a complete injury withdrew from the programme for personal reasons.

\section{Procedures and methods}

The pilot project comprised 2 phases of exercise. The strengthening phase involved a 12 week programme of surface electrical stimulation of the quadriceps and hamstring muscle groups. Stimulation was achieved using a dual channel Myocare stimulation unit, and stimulation parameters mentioned previously. The stimulation pulse train alternated between the right and left legs, 8

Table I Selection criteria

1 Good health

2 Upper motor neuron lesion

3 Incomplete or complete lesion

4 Muscle response to trial stimulation

5 No history of cardiac abnormalities

6 No previous muscle disease

7 No recent pressure sores

8 A low level of spasticity

9 Minimal muscle contractures

10 No recent bone fractures

11 No severe joint calicification seconds on and 10 seconds off, for a twenty minute period. This phasing produced approximately 45 muscle contractions. ${ }^{6,9}$ The aim of the home-based strengthening phase was to familiarise the patients with the stimulation protocol and exercise routine, evoke preliminary increases in lower limb muscle strength and endurance and recondition joint mobility.

The second or cycling phase, using the exercise system already described, commenced 2 weeks after the completion of the strengthening phase and also lasted 12 weeks. Existing EMG data on cycling was used to determine the timing sequence for each subject. ${ }^{13,14}$ The leg muscles were stimulated according to crank position and therefore the timing sequence was self correcting for different rotation velocities.

The programme was conducted 3 times a week for at most 20 minutes per day. When 20 minutes of continuous cycling at $50 \mathrm{rpm}$ could be achieved by the subject, load was added in approximately $1 \mathrm{kgf}$ increments. This was done using a calibrated bandbrake attached to the flywheel of the cycle. The speed of cycling was then set to what was most comfortable for the subject to maintain, without going below $50 \mathrm{rpm}$. The subject with a complete spinal injury could not cycle unaided and required the operator to assist when the speed of cycling slowed. Sessions for this subject were initially divided into 5 minutes of cycling and 5 minutes of rest. The amount of cycling and the number of repetitions were then increased to 20 minutes of total cycling time.

The daily cycling session ended prematurely if (i) the subject was unable to

Table II Clinical characteristics of subjects

\begin{tabular}{lcccccc}
\hline Number & Subject & Gender & Age & Level & $\begin{array}{c}\text { Date of } \\
\text { accident }\end{array}$ & Lesion \\
\hline 1 & JC & M & 27 & T12/L1 & 1985 & INC \\
2 & AE & M & 25 & T10 & 1983 & C \\
3 & ME & F & 38 & T6 & 1972 & C \\
4 & TM & M & 22 & T12/L1 & 1982 & INC \\
5 & MP & M & 28 & T12/L1 & 1976 & INC \\
6 & RW & M & 35 & T11 & 1976 & INC \\
\hline
\end{tabular}

INC $=$ Incomplete lesion

$\mathrm{C}=$ Complete lesion 
maintain the set cycling rate $+/-10 \mathrm{rpm}$, or (ii) an unnatural change in heart rate, ECG pattern, surface skin temperature or patient response occurred.

Heart rate and surface skin temperature at the forearm, thigh, calf and hallux ${ }^{15}$ were monitored at 2-minute intervals during each cycling session and blood pressure was measured prior to and at the completion of each session. A Hewlett Packard 78352A physiological monitor and Squirrel Temperature Data Logger were used. Stimulation electrodes were held in position during the cycling by tubular netting placed over the thigh (Fig 3).

A number of physiological and morphological variables were measured, prior to the project commencing (Table III).

To determine midfemoral cross-sectional muscle area and muscle density single energy CT scans were taken using a Phillips Tomoscan 310 scanner. The midfemoral site was determined as half way between the superior aspect of the greater trochanter of

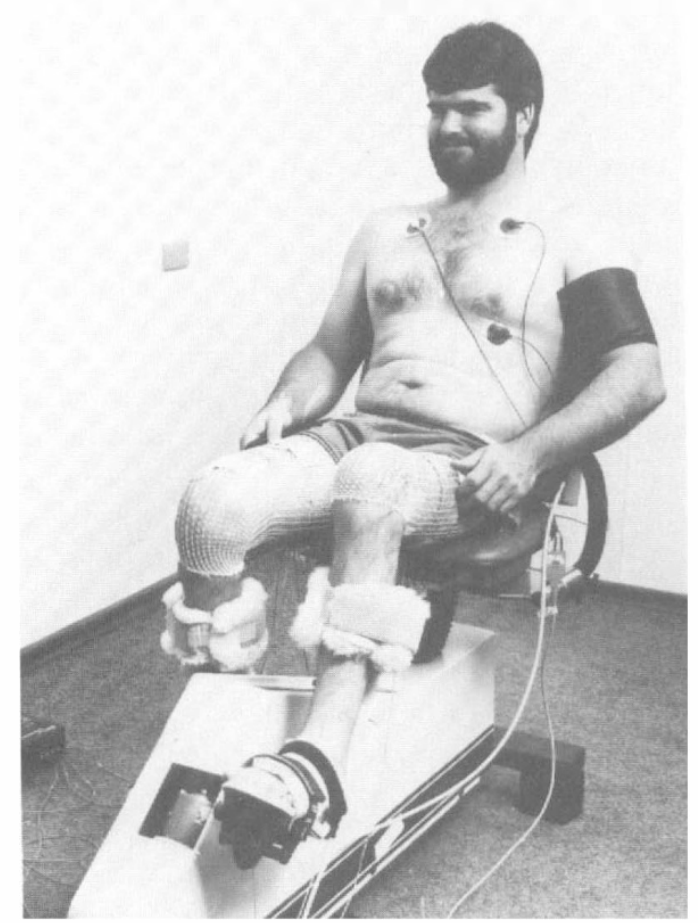

Figure 3 Subject MP on exercise session.
Table III Parameters measured

1 Muscle cross-sectional area

2 Muscle density

3 Lipid profile

4 Level of urinary creatinine

5 Stimulation induced quadriceps strength

6 Stimulation induced quadriceps endurance

7 Ischial and trochanteric sitting pressures

8 Resting heart rate and blood pressure

9 Body weight

10 Voluntary motor output

11 Joint range of motion

12 Thigh circumference

the femur and the lateral tibio-femoral junction. ${ }^{16-18}$ Projection of the CT scan images enabled the boundaries of total muscle, individual muscle compartments and adipose tissue to be visually defined, their perimeters digitised and crosssectional areas calculated using a computer based planimetric technique. The hamstring group was treated as a unit due to difficulty in defining individual muscles.

Muscle density was calculated from the CT scans using 2 methods. The first was based on a regression line of Hounsfield number against density, determined using data published by Woodard and White. ${ }^{19}$ The second used a method developed by Henson et $a l^{20}$ in which animal fat and muscle samples placed on the skin during the scan provided a 2 point calibration of $\mathrm{CT}$ number versus density. Muscle densities were determined for selected sample areas within rectus femoris, vastus lateralis, vastus medialis and 3 areas within the hamstrings for both left and right thighs.

A strain gauged cantilever beam was used to measure stimulation induced quadriceps strength, under isometric conditions (Fig 4). The action of sartorius, though small, could not be separated from the action of the quadriceps and was included in the measurement. The strain beam was attached to a modified SALCO wheelchair and was firmly fixed across the tibial shaft. Three trials were performed at 3 stimulation amplitude levels $(50,75$ and $90 \%$ of maximal output) and at 2 angles of extension (30 and 60 degrees), for both legs. ${ }^{21}$ A 10 second rest period separated each trial. The 


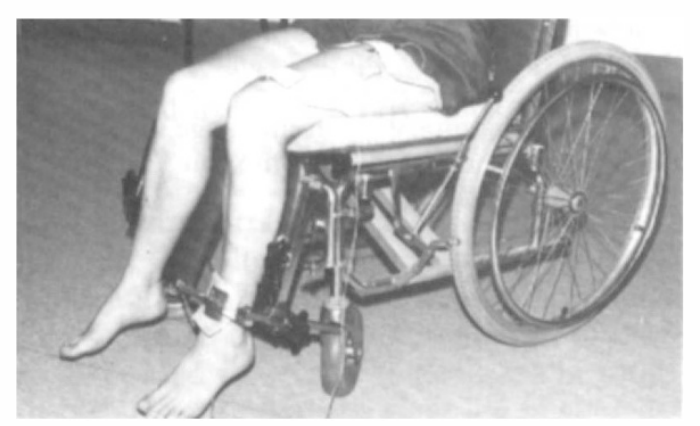

Figure 4 The strength measuring device.

stimulation induced endurance of the quadriceps, under isometric conditions, was also determined using the force measuring device. Again the action of sartorius was included. Time to fatigue was calculated as the time taken for a stimulation induced maximal contraction to drop to $50 \%$ of its output. ${ }^{22}$ Two trials were performed at each stimulation level $(75 \%$ and $90 \%)$ for both legs.

A standard neurological muscle chart of both legs was recorded by a trained physiotherapist. This provided grade indication of neurological motor deficit, residual motor output, joint range of motion and the presence of joint contractures. Girth measurements, using an anthropometric tape, were made at the midfemoral and maximal calf sites. An average of 3 readings was used. Resting heart rate and blood pressure were measured using the Hewlett Packard physiological monitor. Measurements of ischial and trochanteric contact pressure were recorded using a clinical pressure transducer, with the subject seated on a standard flat cushion. ${ }^{23}$ Body weight was measured using balance chair scales. Urine samples were taken under fasting conditions to determine levels of urinary creatinine, an indicator of the amount of protein in the body. A blood sample was also taken to determine lipid profile. All tests were repeated following both the strengthening and cycling phases.

\section{Analysis}

Due to the small sample size and high inter-subject variability the patient results were assessed as individual case studies. ${ }^{24}$ Change in the parameters was determined using estimates of test repeatability measured before or during the programme or published by other investigators. Results obtained after the strengthening phase of the programme were not considered separately.

\section{Results}

\section{Repeatability}

Tests of repeatability were conducted on the strength, endurance and muscle crosssectional area measurements. Stimulation induced quadriceps strength displayed a repeatability of $+/-2 \mathrm{Nm}$. This value was determined from the mean difference in torque following consecutive strength measurements for all subjects. The stimulation induced endurance of the muscle varied by $+/-10$ seconds, calculated from the mean difference of the 2 trials conducted at each measurement session for all subjects. Muscle cross-sectional area, measured using CT, was found to have an error of $+/-5 \%$. This measure, obtained by digitising a known object in 10 different scans, represented a composite value of errors incurred during the CT scanning and digitising procedure. Others have reported a similar figure. ${ }^{16,18,25,26}$ Repeatability of density and girth measurements was obtained from work previously published. Ackland et al $^{27}$ reported a $+/-5 \%$ difference between CT derived density values and directly measured mass density. The error was attributed to scan noise, patient movement and the transference of selected regions of interest across repeated scans. The repeatability of girth measurements using an anthropometric tape was reported by Borms et $a l^{28}$ to be $+/-2 \mathrm{~mm}$.

\section{Case studies}

Results for 7 of the parameters for the 5 subjects are presented in Table IV. Lipid profile, level of urinary creatinine, sitting contact pressures and resting heart rate and blood pressure showed no change over the course of the programme for any of the subjects and are not included. Exercise tolerance results, obtained from the cycling 
Table IV Results for cross-sectional area, muscle density, stimulation induced strength and endurance of the quadriceps, voluntary motor output, joint range of motion and thigh girth

\begin{tabular}{|c|c|c|c|c|c|c|c|}
\hline Subject & Area & Density & $\begin{array}{c}\text { Strength } \\
\text { (stimulation } \\
\text { induced) }\end{array}$ & $\begin{array}{l}\text { Endurance } \\
\text { (stimulation } \\
\text { induced) }\end{array}$ & $\begin{array}{l}\text { Voluntary } \\
\text { motor } \\
\text { output }\end{array}$ & $\begin{array}{l}\text { Joint range } \\
\text { of motion }\end{array}$ & $\begin{array}{l}\text { Thigh } \\
\text { girth }\end{array}$ \\
\hline $\mathrm{JC}$ & + & 0 & 0 & + & 0 & 0 & 0 \\
\hline $\mathrm{ME}$ & + & + & 0 & + & 0 & 0 & + \\
\hline $\mathrm{TM}$ & 0 & 0 & $\mathrm{NM}$ & NM & + & + & 0 \\
\hline MP & $\begin{array}{l}-(\mathrm{R}) \\
0(\mathrm{~L})\end{array}$ & 0 & + & + & + & + & 0 \\
\hline RW & + & 0 & 0 & 0 & + & + & + \\
\hline
\end{tabular}

phase of the programme, are presented in Table V.

\section{Discussion}

The results of this study indicate that 24 weeks of stimulation induced exercise increased the exercise tolerance of all 5 participating subjects. This agrees with the findings of previous investigations. ${ }^{2,6,7,9,29}$

A progressive increase in treatment time, cycling rate and exercise load was noted over the course of the programme. This increase was directly attributed to strength and endurance improvements at the local muscle level, as opposed to an increase in central cardiovascular performance. Local muscle fatigue always preceded central cardiovascular fatigue and exercise heart rate remained low in all subjects. Resting heart rate and blood pressure were not altered over the course of the programme.

Many authors have reported stimulation induced strength increases ${ }^{5,30-33}$ following electrical stimulation of atrophied muscle.
Others have shown increases in muscle endurance. $6,9,29,34,35$ A number of these investigators have used an exercise cycle to elicit these changes.

The stimulation induced strength and endurance measures in this study were subject to error and in some cases did not support the exercise tolerance findings. Only one subject demonstrated an increase in quadriceps strength after the programme while 3 subjects displayed increases in endurance. One subject could not be measured. The error was attributed to biological variability, equipment shortcomings and variation in the placement of electrodes.

While the stimulation induced strength results were poor, an increase in the voluntary strength of 3 out of 4 incomplete subjects was demonstrated by the neurological muscle grading. In addition, the active joint range of motion of the knee or hip improved in 3 out of 4 subjects with incomplete injuries.

Total muscle area and individual muscle

Table V Results for exercise tolerance

\begin{tabular}{lcccccc}
\hline Subject & \multicolumn{2}{c}{ Before programme } & \multicolumn{3}{c}{ After programme } \\
& Duration & Speed & Load & Duration & Speed & Load \\
\hline JC & $20 \mathrm{mins}$ & $50 \mathrm{rpm}$ & $2.5 \mathrm{kgf}$ & $20 \mathrm{mins}$ & $50 \mathrm{rpm}$ & $7.0 \mathrm{kgf}$ \\
ME & $5 \mathrm{mins}$ & $30 \mathrm{rpm}$ & $0 \mathrm{kgf}$ & $21 \mathrm{mins}$ & $40 \mathrm{rpm}$ & $0 \mathrm{kgf}$ \\
TM & $10 \mathrm{mins}$ & $40 \mathrm{rpm}$ & $0 \mathrm{kgf}$ & $20 \mathrm{mins}$ & $50 \mathrm{rpm}$ & $3.0 \mathrm{kgf}$ \\
MP & $20 \mathrm{mins}$ & $55 \mathrm{rpm}$ & $0 \mathrm{kgf}$ & $20 \mathrm{mins}$ & $65 \mathrm{rpm}$ & $5.5 \mathrm{kgf}$ \\
$\mathrm{RW}$ & $10 \mathrm{mins}$ & $40 \mathrm{rpm}$ & $0 \mathrm{kgf}$ & $20 \mathrm{mins}$ & $50 \mathrm{rpm}$ & $2.25 \mathrm{kgf}$ \\
\hline
\end{tabular}


compartments of the thigh increased in 3 out of 5 subjects. The increases were more pronounced in the severely weakened muscles and the subject completely paralysed as compared to the incomplete subjects. This result supports previous investigators $2,7,8,26,30,36$ who have found muscle hypertrophy and a concomitant increase in muscle cross-sectional area after stimulation of disuse atrophied muscle. The decrease in total muscle area found in the right leg of subject MP is difficult to explain. An increase in the cross-sectional area of the right rectus femoris, vastus lateralis and hamstrings after the programme suggests that one or more of the remaining thigh muscles decreased in area. The reason for this is unclear. An increase in the area of the left rectus femoris was also found for this subject while no change occurred in left total muscle area. In most cases increases in midfemoral girth measurements taken at regular intervals during the programme correlated with the recorded increases in CT measured muscle area. However girth measurements are subject to error and influenced by changes in adipose tissue. This can be seen in subject JC, where an increase in total muscle area was not accompanied by an increase in girth. A decrease in the adipose thickness was noted in this subject. Little change was found in muscle density, with an increase only noted in subject ME using the Henson method. However several difficulties affected this measurement. These included CT artifacts (streaking and shadowing) and the severity of muscle atrophy in some subjects. Ragnarsson $^{8}$ suggested from observations of midfemoral CT sections that electrically stimulated paralysed muscle showed a trend toward increased muscle density and a reduction in intramuscular fat. The selection of a region of interest for the calculation of muscle density, however, was highly specific to avoid areas of streaking, water regions and areas of fat. A profile of density across the entire muscle compartment would be a more valid indicator of stimulation induced changes in muscle homogeneity and uniformity.

No change was recorded in the trochanteric and ischial tuberosity sitting pressure readings as a result of the FES exercise programme. It has been shown that direct electrical stimulation of the gluteal region can change the shape of the loaded buttocks which may assist in preventing pressure sores over the seating surface. ${ }^{37,38}$ However the stimulation profile used in this study was limited in the upper hamstring and was not of a sufficient intensity to involve the gluteal muscles. Exercise of the lower limbs without the involvement of the gluteal muscles does not appear to influence sitting pressures.

Following the programme all incomplete SCI subjects reported greater ease in transferring and dressing, an ability to stand and walk with stability and regularity, more effective use of the thigh muscles and general enhancement of functional abilities. As the FES programme progressed little or no muscle spasticity was recorded in the knee extension strength test, indicating a general reduction in muscle spasticity. This was subjectively reported by 2 of the participating subjects and agrees with previous investigators. ${ }^{34,39,40}$

Three of the 5 subjects expressed a desire to continue their participation in the FES programme beyond a research capacity, and as such have encouraged the transition of the exercise programme to the clinical environment and the development of a home unit.

The exercise system developed for the research programme was simple and could be operated by one person using commercially available stimulation units. Future developments include a motor assist for patients incapable of cycling unaided, better control of exercise load and an improved pedal arrangement to prevent knee varus or valgus.

\section{Conclusions}

It has been demonstrated that an exercise programme comprising stimulation induced strengthening and cycling phases increased exercise tolerance, as determined by a progressive increase in treatment time, cycling rate and exercise load. As a result of electrical stimulation increases were found in voluntary muscle strength, stimulation 
induced muscle endurance, muscle crosssectional area, active joint range of motion and functional capabilities. No change was found in midfemoral muscle density. Problems were encountered in the measurement of some of the parameters, especially stimulation induced muscle strength and density, which are to be addressed in future studies.

The exercise cycle demonstrated the feasibility of providing spinal injured patients with an accepted aerobic exercise. Improvements to the system will widen its use amongst the patient population and in a clinical setting. Further developments are needed to produce a low cost home based unit.

\section{Acknowledgements}

This project has been funded by the Medical Research fund of Western Australia (MEDWA) and supported by Royal Perth and Royal Perth Rehabilitation Hospitals. The assistance of David Guy, Trevor Jones, Eric Swarts, Cathie Stewart, Peter Henson, Peter Briedahl and Ruth Harrison is gratefully acknowledged.

\section{References}

1 Guttman HL (1976) Spinal Cord Injuries - Comprehensive Management and Research. Blackwell Scientific, Oxford.

2 Petrofsky JS, Phillips CA (1984) The use of functional electrical stimulation for rehabilitation of spinal cord injured patients. Cent Nerv Sys Trauma 1(1): 57-73.

3 Petrofsky JS, Phillips CA, Stafford DE (1984) Closed loop control for restoration of movement in paralysed muscles. Orthopaedics 7: 1289-1302.

4 Petrofsky JS, Phillips C, Almedyha J, Briggs R, Couch W, Colby W (1985) Aerobic trainer with physiological monitoring for exercise in paraplegic and quadriplegic patients. J Clin Eng 10(4): $307-316$.

5 Phillips CA, Petrofsky JS, Hendershot DM, Stafford D (1984) Functional electrical stimulation: a comprehensive approach for physical conditioning of the spinal cord injured patient. Orthopaedics 7(7): 1112-1123.

6 Glaser RM (1986) Physiologic aspects of spinal cord injury and functional neuromuscular stimulation. Cent Nerv Sys Trauma 3(1): 49-62.

7 Pacy PJ, Hesp R, Halliday DA, Katz D, Cameron G, Reeve J (1988) Muscle and bone in paraplegic patients and the effect of functional electrical stimulation. Clin Sci 75: 481-487.

8 Ragnarsson KT (1988) Physiologic effects of functional electrical stimulation induced exercises in spinl cord injured individuals. Clin Orthop Rel Res 233: 53-63.

9 Ragnarsson KT, Pollack S, O'Daniel W, Edgar R, Petrofsky J, Nash MS (1988) Clinical evaluation of computerised functional electrical stimulation after spinal cord injury: a multicentre pilot study. Arch Phys Med Rehabil 69: 672-677.

10 Baker LL (1981) Neuromuscular electrical stimulation in the restoration of purposeful limb movement. In: Wolf SL, editor. Electrotherapy. Churchill Livingstone, New York: 25-48.

11 Benton LA, Baker LL, Bowman BR, Waters RL (1981) Functional Electrical Stimulation - A Practical Clinical Guide. Rancho Loss Amigos Rehabilitation Engineering Centre.

12 Alon G, Allin J, Inbar G (1983) Optimisation of pulse duration and pulse charge during transcutaneous electrical nerve stimulation. Aust J Physiother 29(6): 195-201.

13 Faria I, Cavanagh P (1978) The Physiology and Biomechanics of Cycling. John Wiley and Sons, New York.

14 Ericson MO, Nisell R, Arborelius UP, Ekholm J (1985) Muscular activity during ergometer cycling. Scand J Rehabil Med 172: 53-61.

15 Ramanathan NL (1964) A new weighting system for mean surface temperature of the human body. $J$ Appl Physiol 19: 531-535.

16 Ingemann-Hansen T, Halkjaer-Kristensen J (1980) Computerised tomographic determination of human thigh components. Scand J Rehabil Med 12: 27-31.

17 Young A, Hughes I, Russell P, Parker MJ, Nichols PJ (1980) Measurement of the quadriceps muscle wasting by ultrasonography. Rheumatol Rehabil 19(3): 141-148.

18 Maughan R, Watson J, Weir J (1983) Strength and cross-sectional area of human skeletal muscle. J Physiol 338: $37-49$.

19 Woodard HQ, White DR (1986) The composition of body tissues. Br J Radiol 59: 1209-1219.

20 Henson PW, Ackland T, Fox RA (1987) Tissue density measurement using CT scanning. Aust Phys Eng Sci Med 10(3): 162-166.

21 Kralj A, Bajd T, Turk R (1980) Electrical stimulation providing functional use of paraplegic patient muscles. Med Progr Through Technol 7: 3-7.

22 Trnkoczy A (1987) Functional electrical stimulation of extremities: its basis, technology and role in rehabilitation. Automedica 2: 59-100.

23 Noble PC (1981) The prevention of pressure sores in persons with spinal cord injuries. International Exchange of Information in Rehabilitation, New York. 
24 Ottenbaher KJ (1986) Evaluating Clinical Change - Strategies for Occupational and Physical Therapists. Williams and Wilkins, Baltimore.

25 Haggmark T, Jansson E Svane B (1978) Cross-sectional area of the thigh in man measured by computer topography. Scand J Clin Lab Invest 38: 355-360.

26 Block JE, Steinback LS, Freidlander AL, Steiger P, Wladislaw E, Morris JM et al (1989) Electrically stimulated muscle hypertrophy in paraplegia: assessment by quantitative CT. J Comput Assist Tomogr 13(5): 852-854.

27 Ackland T, Henson PW, Bailey DA (1988) The uniform density assumption: its effect upon the estimation of the body segment inertial parameters. Int J Sports Biomech 4: 146-155.

28 Borms J, Hebbelinck M, Carter JEL, Ross WD, Lariviere G (1979) Standardisation of basic anthropometry in Olympic athletes: the MOGAP procedure. In: Methods of Functional Anthropology. University Carolina Progensis: $31-39$.

29 Pacy P, Evans R, Halliday D (1987) Effect of anaerobic and aerobic exercise promoted by computer regulated functional electrical stimulation on muscle size, strength and histology in paralegic males. Prosthet Orthot Int 11: 75-79.

30 Kralj JA, Grobelnik S (1973) Functional electrical stimulation: new hope for paraplegic patients. Bull Prosthet Res 10: 75-102.

31 Marsolais EB, Kobetic R (1983) Functional walking in paralysed patients by means of electrical stimulation. Clin Orthop Rel Res 175: 30-36.

32 Fournier A, Goldberg M, Green B, Brucker B, Petrofsky J, Eismont F et al (1984) A evaluation of the effects of computer assisted muscle stimulation in paraplegics patients. Orthopaedics 7: 1129.

33 Holle J, Frey M, Gruber H, Kern H, Stohr H, Thoma H (1984) Functional electrostimulation of paraplegics: experimental investigations and first clinical experience with an implantable stimulation device. Orthopaedics 7: 1145.

34 Kralj A, Bajd T (1989) Functional Electrical Stimulation: Standing and Walking after Spinal Cord Injury. CRC Press Inc, Florida.

35 Pollack SF, Axen K, Speilholz N, Levin N, Haas F, Ragnarsson KT (1989) Aerobic training effects of electrically induced lower extremity exercise in spinal cord injured people. Arch Phys Med Rehabil 70: 214-219.

36 Munsat T, McNeal D, Waters R (1976) Effects of nerve stimulation on human muscle. Arch Neurol 33: 608-617.

37 Levine S, Kett R, Cederna P, Bowers L, Brooks S (1989) Electrical muscle stimulation for pressure variation at the seating interface. J Rehabil Res Dev 26(4): 1-8.

38 Levine S, Kett R, Cederna P, Brooks S (1990) Electric muscle stimulation for pressure sore prevention: tissue shape variation. Arch Phys Med Rehabil 71: 210-215.

39 Levine M, Knott M, Kabat H (1952) Relaxation of spasticity by electrical stimulation of antagonistic muscles. Arch Phys Med Rehabil 33: 673-688.

40 Shindo N, Jones R (1987) Reciprocal patterened stimulation of the lower limbs in severe spasticity. Physiotherapy 73: 579-582. 